\title{
İnovatif Çözüm Yaklaşımı: Genç İşsizlik Vaka Çalışması
}

\section{$\ddot{\mathbf{O} z}$}

Bu makale bir problemin, tasarım düşüncesi inovasyon yaklaşımı ile nasıl çözüldügüünü göstermektedir. Sorun olarak ele alınan konu toplumdaki en temel sıkıntılardan biri olan genç işsizliktir. Özellikle de mesleksiz olanlara odaklanılmaktadır. Bireyin genç, tecrübesiz ve niteliksiz olması çözümü zorlaştırmaktadır. Bu tip karmaşık ve kördügüm problemlerin çözümünde tasarım düşüncesi yöntemi; kullanıcı odaklı, ekip çalışmasına dayanan, deneme-yanılmaya dayalı olması bakımından oldukça etkilidir. Çözüm yaklaşımında ekip sırayla şu adımları takip etmiştir: Kendi hikayeni paylaşma, başarı hikayelerini belirleme, mülakatlar gerçekleştirme, başkasının adımıyla ilerleme, yeni gözlerle bakma (alternatif dünyalar), şaşırtan noktalart keşfetme, prototipleme, geri bildirim almadir (saha çalışmasıdır). Bu çalışma göstermiştir ki; tasarım düşüncesi yöntemiyle bir sorun empatik olarak anlaşılır, farklı sektörlerden ilham alınarak fikirler üretilir ve deneme amaçlı prototipler yapılır. Bu bakımdan, tasarım düşüncesi bir süreçtir ve inovasyonun yaratıcllıktan ziyade bir disiplin işi olduğunu savunmaktadır.

Anahtar Kelimeler: Genç işsizlik, inovasyon, tasarım düşüncesi, alternatif dünyalar, saha çalışması

\section{Innovative Problem Solution: Youth Unemployment Case Study}

\begin{abstract}
This article shows how design thinking approaches a problem to solve. The issue of youth unemployment, which is one of the main obstacles in society. In particular, the focus was on those who have a lack of education. The fact that the individual is young, inexperienced and unqualified makes the solution difficult. The user-oriented, team-based, trial-and-error method of design thinking is beneficial in these types of complex problems. The team followed these steps: share your own story, identify success stories, conduct interviews, progress with someone else's steps, look with new eyes (alternative worlds), discover surprising points, prototyping, feedback. This study showed that design thinking method, the team understands a problem empathetically, produces ideas by getting inspiration from other sectors, and builds prototypes for testing purposes. In this regard, design thinking is a process and sees innovation as a discipline rather than creativity.
\end{abstract}

Keywords: Youth unemployment, innovation, design thinking, alternative world, field study

\footnotetext{
*ORCiD Prof. Dr., Erzincan Binali Yıldırım Üniversitesi, İ̈BF, mustafa.akin@erzincan.edu.tr
} 


\section{Extended Abstract}

DT is a systematic and iterative process for finding and solving complex problems. It is building a deep empathy with the people we are designing for (ethnographic research), generating many ideas (brainstorming), building prototypes (prototyping), showing them to the people we are designing for (ethnographic testing), and developing products through iteration.

There are several characteristics of DT:

$D T$ is a user-focus. A user-focus organization can know and understand our customers, listen to expressed needs, anticipate the unexpressed ones, and deliver superior customer experiences for them. Who are our users? Not just demographics-wise, but what are their motivators and behaviors? What does value look like to them? What is their expectation?

DT is about finding opportunities for us to help users live their life better. If we think about technology, pain points, latent needs as opportunities, we can start thinking about different users, people, technologies, ideas and putting them together. Our job is to expand our thinking as widely as possible, take in lots of new ideas and information, and quickly imagine different approaches and solutions. It is essential to remain open, take in all kinds of information through ethnographic studies, and try not to prejudge a problem before understanding it.

DT is a method-crossing discipline that allows people to brainstorm explosively and iteratively try to solve problems. It is a process that knowledge workers use to more effectively research and design and test out ideas, particularly how they affect people.

$D T$ is an iterative process. It continually tests hypotheses and alters based on findings. We test everything, and we assume nothing. It starts with a minimal investment of time and money, devotes resources over time. If we have a venture that we cannot test the idea, DT recommends not investing.

The main difference between DT and other great methods of innovation is the human focus and the diverse team effort. Therefore, DT is also called human-centered design. Diversity indicates different backgrounds of people who work with the DT principles. DT is about building empathy with users. An individual thinks and acts with feelings. We primarily aim at emotional improvements rather than functional ones. If something does not work, it will make people angry. As designer thinkers, we do not want to get people frustrated. However, angry and frustrations are negative feelings.

In this work, we apply DT methods to youth unemployment. We follow these steps:

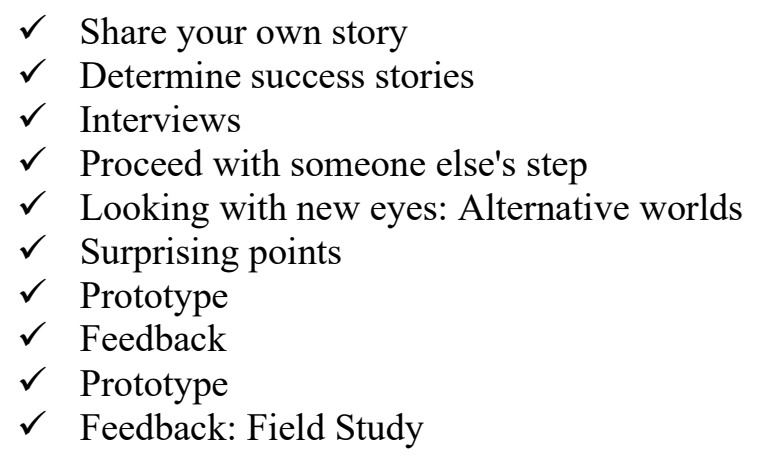

The flow of knowledge through conferences is not effective. When the youth people face real job environments and meet with bosses and employees, they get the essence of jobs through first-hand experience. 


\section{Giriş}

Genç insanların kariyerlerini olumsuz etkileyen en önemli sebeplerden biri eğitimlerini terk etmeleri ve sonucunda yaşadıkları işsizliktir. Okulu terk eden öğrenciler iyi bir iş bulmakta zorlanıyorlar ve düşük kaliteli bir hayata itiliyorlar. Bahçeşehir Üniversitesi Ekonomik ve Toplumsal Araştırmalar Merkezi (BETAM) yaptığı bir araştırmada Türkiye'de 15-19 yaşlarında 1,4 milyon gencin okulu bıraktığını ve herhangi bir iş yerinde çalışmadıklarını tespit etmiştir (Betam, 2019: 2). Ayrıca çalışan gençlerin umut vaat eden bir işte çalışıp çalışmadıkları da sorunun bir başka boyutudur. BETAM araştırmasında gençlerin eğitimi için acil politikalar geliştirilmesi gerektiğine işaret etmektedir. Geleneksel analitik bakış açısında daha iyi eğitim gibi çözümlemeler kamu politikalarına 1şık tutmada çok yetersiz kalmaktadır. Bu politikaların oluşturulmasında inovatif çözümler için yöntem eksiği vardır. ABD'nin en yaratıcı bölgesi olan Silikon Vadisi'nde kamu ve özel sektöre tasarım düşüncesi sistemiyle çözüm sunan IDEO firmasının (Kelley, 2005) yöntemlerinden nasıl faydalanacağı makalede gösterilecektir.

Tasarım düşüncesinin mesleksiz ve işsiz gençlere yönelik saha çalışmasından elde edilecek geri bildirimler 1şığında yaratıcı çözüm önerilerine ihtiyaç vardır. Daha iyi eğitim politikaları yanında başka yaratıcı çözümler üretilebilir. Bu makale genç işsizlik üzerinden tasarım düşüncesi modelini takip ederek empatik yaklaşımla inovatif çözümlerin bulunuşunu göstermektedir.

2020 y1lı itibariyle ABD'de 16 ile 24 yaş arasında 4 milyon gencin lise diploması yoktur (OECD, 2020: 1). ABD'de lisedeyken okul terkin her y1l yükseldiği ve özelikle azınlıklar arasında bu oranın \%50'lere ulaştı̆̆ görülmektedir (Lee ve Burkam, 2003: 2). Akademik çalışmalarda okulu terk edenlerin zekalarının normal olduğu, ancak derslerden sıkılmalarının, motivasyon eksiklerinin ve kendi ilgi alanların dışında oluşturulmuş materyallerden olumsuz etkilendikleri anlaşılmaktadır (Bill ve Melinda Gates Foundation, 2013).

Çevresel faktörler, eğitim kalitesi, ebeveynlerin yaklaşımı, devletin kapasitesi nitelik eksiği olan bir gencin sorunun çözümünü zorlaştırmaktadır. Sosyal refahı ciddi şekilde etkileyen devasa problemlere nasıl çözüm üretilir? Bu makalede tasarım düşüncesi sistemi kullanılarak okulu terk edenlerin iş hayatıyla bağlantılarını sağlayacak destekleyici bir modelin nasıl kurgulanacağı gösterilmektedir.

\section{Tasarım Düşüncesi Yaklaşımı: Prensip ve Yöntem}

Tasarım düşüncesi sorun çözme sürecini tasarımcılardan almıştır (Brown, 2009). Tasarımcıların bir nesneyi ortaya çıkarmak veya ilerletmek için kullandıkları araçlar ve bakış açıları süzülmüştür. Örneğin bir mobilya veya takı için kullanılan süreç bir sağlık servisinin veya organizasyon şemasının yeniden inşa edilmesi için kullanılmaya başlanmıştır. Bir kurum tasarım düşüncesini benimsediğinde, çalışanların problemi tanımlama, fırsatları keşfetme ve belirsizlikte iz bulma yöntemlerini de öğrenmiş olurlar. Ancak tasarım düşüncesinde hedef tasarım ürünü bulmaktan ziyade, tüm ekonomik ve teknolojik aktiviteler için kullanıcı deneyimi kavramları üretmeye geçmiştir.

İnovasyon ve girişimcilik yükssek belirsizliğe sahiptir. İnovasyon ve girişimcilikte başarı olasılığı çok düşüktür. Önemli bir kayıptan kaçınmak ve inovasyonda başarı ihtimalini yükseltmek için tasarım düşüncesi prensipler ve yöntemler geliştirmiştir.

Tasarım düşüncesi bir problem-çözüm sistemi olarak kullanıcı odaklı, ekip çalışmasına dayanan, deneme-yanılma yöntemidir (Luma Institute, 2014: 55; Brown, 2008: 60). Prensipler: Kullanıcı odaklılık ve empati, problemi bölme ve tanımlama, görselleştirme, deneyimsel, bağlamsal ve bütünsellik, deney, yineleme ve hata, farklı ekip, farklı ve yakınsak düşünme, 
deneyimsel üründür (Akın, 2020: 34-36). Bu prensiplere göre hareket eden düşünce inovasyon süreci tasarım düşüncesidir (Dorst, 2011: 522).

Araştırmada yöntem olarak olarak etnografi, beyin firtınası ve prototip kullanılmaktadır (Klein, 2013: 73-75). Etnografik yöntemlerle kullanıcıdan derin iç görüler almaktır. Beyin firtınası yeni fikirler üretmektir. Prototiplemede, zaman harcamadan yeni fikirlerin nasıl uygulanacağı konusunda rehberlik etmektir.

Tasarım düşüncesi temelde teori yerine aksiyon odaklıdır. Fikirlerin prototipini yapmayı paydaşlara göstermeyi, geri bildirim almayı ve sürekli olarak bu deneme-yanılma sürecini tekrarlamayı öngörmektedir.

Tasarım düşüncesi kullanıcıların hayatlarını daha iyi yaşamasına yardımcı olacak firsatlar bulmakla ilgilidir. Bir girişimci kullanıcıların karşılaştıkları acı noktaları ve gizli ihtiyaçları yakaladıktan sonra, çözümleri bulup, insan sermayesini, teknolojiyi, fiziksel kaynakları bir araya getirilebilir.

Tasarım düşüncesinin teknolojik inovasyon yöntemlerinden temel farkı, insan odaklı olması ve çeşitli alanlardan gelen ekiplerin beraber çalışmasıdır (Beverly, 2013: 95-99). Bu nedenle tasarım düşüncesine, insan merkezli tasarım olarak da adlandırılır. Ekipteki çeşitlilik, tasarım düşüncesi ilkeleriyle çalışan farklı deneyimlere ve eğitimlere sahip kişilerin beraberliğini göstermektedir.

Tasarım düşüncesi, kullanıcılarla empati kurmakla ilgilidir. Birey duygularla düşünür ve hareket eder. Öncelikle işlevsel olmaktan ziyade duygusal gelişmeler hedeflenmektedir. Kullanıcıların hayatlarını (statü, beklentiler, duygular, aktiviteler, bağlantılar) öğrendikten sonra inovasyon için sınırsız bir alan vardır.

Pazar araştırmasına kıyasla tasarım düşüncesinde benzersiz olan, araştırmanın amacının yaşam kalitesi ilerletmek ve çıktı beklentisinin olmamasıdır. Tasarım düşüncesinde ne inşa edileceği üzerine belirli bir ürün veya fikir yoktur. Bunun yerine kullanıcıya ve firsatlara odaklanılır.

Teknoloji ve iş öncelikleri yerine, kullanıcılar yeniliğin birincil kaynă̆ıdır. Tasarım düşüncesinde rekabetçi avantajın kaynağı kullanıcıyı anlamaktır. Süreç empatiyle başlamakta, ekip kendisini kullanıcın yerine koyarak pazara deneysel ürün sunmaktadır. Kullanıcılara daha hızlı bir şekilde odaklananlar kazanmaktadır. Gerek işletmeyi gerekse teknoloji bu odaklanma üzerine inşa edilmelidir. Kullanıcılar tasarlanan deneyimi beğenirse, teknoloji geliştirme ve gelir yaratma takip etmektedir. Kullanıcıların sadakatine sahip olma üretime sahipliğinden çok daha önemlidir (Lietdka ve Ogilvie, 2011:90).

Tasarım düşüncesi, kullanıcı deneyimini ortaya çıkarmak için gözlem, mülakat, denemeyanılma, kendisini başkasının yerine koyma gibi etnografik odaklılığı araştırmayı kapsar. Geleneksel iş disiplinleri operasyonel etkinlik ve bilimsel araştırma varsayımlarla ilerlerken, tasarım düşüncesi empati esaslı, kullanıcı odaklı, ekip çalışmalı, prototiplerle ve denemeyanılmayla ilerler. Sahada çalışanların pratikteki deneyimleri esastır (Lietka vd., 2014: 90-110).

Öncelikle işlevsel (fonksiyonel) olmaktan ziyade duygusal gelişmeler hedeflenmektedir. Bir ürün fonksiyonel olarak işe yaramazsa, insanları kızdırır. Tasarım düşüncesinde insanları hayal kırıklığına uğratmak istenmez. Kızgınlık ve hayal kırıklıkları olumsuz duygulardır. $\mathrm{Bu}$ açıdan ürün fonksiyonel olarak beklendiği gibi işlemelidir. Bunun ötesinde deneyimlerle kullanıcılar memnun edilir. Ürünlere neşe, enerji, coşku ve romantizm katılır. İnsanlar arkadaşlarıyla, akrabalarıyla ve meslektaşlarıyla paylaştıklarında daha mutlu olurlar. Bu paylaşım anlayışını ürünle birleştirilmek istenmektedir. Bununla birlikte, inovasyona bir duygu katmak kullanıcılar için anlamlı olmalıdır. Girişimciler kullanıcıları tanıyarak onlar için anlam 
içeren duyguları araştırmalılar. Etnografik araştırmalarla ısrarla yaşanan olaylardaki duygular sorulur ve bu duygular üzerinden takip sorularına geçilir.

Tasarım düşüncesinde sadece kullanıcılar için değil, çalışanlar, işletmeler ve toplum için de anlamlı deneyimler ile değerler yaratmak amaçlanmaktadırlar (dört boyut). Birçok şirket anlamlı bir amaç olmadan kâr etmekte ama uzun vadede, kullanıcılar, çalışanlar ve toplum için değerler yaratamadıkları için sıkışmışlardır. Aranılan ana sorular: Bu dört boyut için nasıl farklı bir deneyim yaratılır? Bir çalışan aynı anda hem çalışır ve hem de işten zevk alabilir mi? İşletmenin sahip olan bilgiyi ekosisteme nasıl yayılabilir?

Tasarım düşüncesi tasarım yöntemlerini kullanarak inovasyon yeteneğini geliştirmek isteyen hayal ettiğini henüz keşfedememiş ve keşfettiğini de gerçeğe dönüştürmek isteyenlere yöneliktir.

\subsection{Tasarım Düşüncesi Prensipleri}

Tasarım düşüncesi yönteminin prensipleri şunlardır:

Kullanıcı Odaklılık ve Empati: Tasarım düşüncesinde ana amaç kullanıcıyı dinlemek ve odaklamaktır (Liedtka ve Ogilvie, 2011: 20-25; Kumar, 2012: 270). Araştırmacı kullanıcının hayatta ne istediğini neye ihtiyacı olduğunu bilmelidir. Empatik yaklaşım tüm paydaşların katkılarını sağlamaktadır. Hem paydaşlar hem de ekip ortak kurgulama sayesinde sürece katkıda bulunduklarını hissetmekteler. Kullanıcıların sadece demografik olarak değil, motivasyonları ve davranışları nelerdir? Kullanıcı odaklı bir organizasyon müşterilerini tanıyabilir, anlayabilir, ifade edilen ihtiyaçları dinleyebilir, ifade edilmemiş olanları tahmin edebilir ve onlar için üstün müşteri deneyimleri sunabilir. Kullanıcıları anlamak için "mülakat" ve "kendimizi yerine koyma" gibi araçlara ihtiyaç vardır. Bu metotlarda, müşteriye deneyimleri anlattırılmakta ve müşteri gibi davranılmaktadır. Örneğin bir çağrı merkezindeki etkinliği anlamak için, müşteri hattı aranmaktadır. Ne kadar beklenecek? Ne sıklıkla aktarılmaktadır? Tatmin eden yanitlar alınmakta midir?

Problemi Bölme, Tanımlama, Çerçeveleme: Ekip üyeleri problemi başlangıçta çözmeye odaklanmazlar, fakat temel sorunları anlamaya ve tanımlamaya çalışırlar. Büyük bir problemi çözmek yerine problemi parçalara ayırarak yönetilebilir hale dönüştürülmektedir. Sorunun tanımı yeniden çerçevelenerek sorun kökeninden anlaşılmaya çalışılmaktadır. Çözüm üretirken sürekli olarak problem hatırlanarak devam edilmektedir (Caddick ve Cable, 2011: 75).

Görselleştirme: Görselleştirme görsel materyaller kullanılarak tüm sürecin anlaş1lmas1 sağlanmaktadır. Zihin haritaları ve prototipler görselleşme araçlarıdır (Liedtka vd., 2014: 99101).

Deneyimsel, Bağlamsal ve Bütünsel: Bütünsel bir yaklaşım, sadece kişiyi değil, kişiyle temas eden tüm unsurları gözlemlemektir. Kullanıcıların beklentileri ve dünyaya bakışları incelenmektedir. Tasarım düşüncesi deneyimsel yeniliği hedeflemektedir. Deneyimler duygusal, sosyal, kültürel, bilişsel ve fiziksel temellere dayanır (Kumar, 2012: 326). Fiziksel (veya fonksiyonel) ihtiyaçlar yüzeyseldir ve pek çok ürün bunları karşılamaktadırlar. Duygusal deneyimler derin ve kalıcidır. Kararların \%95'i duygulara dayanmaktadır (Zaltman, 2003: 8899). Kullanıcı merkezli yeniliğin amacı, doğru duyguları bütünsel olarak (doğru ortamda, zamanda ve kullanıcılarda) sağlamaktır (Moisander ve Voltanen, 2011: 220).

Yeni patentler ve teknolojiler ortaya çıkmaktalar ancak asıl soru kullanıcıların bağlamında hangi ihtiyacın karşılanması gerekliliğidir? Fiziksel olmayan deneyimlerini 
önemini göstermek için vücut geliştirme gibi çok yoğun fiziksel güç gerektiren bir faaliyetten örnek gösterilebilir. İnsanlar vücutlarını ağırlık kaldırma aletleriyle eğitirler ve gelişmiş kaslara sahip olurlar. Ancak, çok nadiren bu kadar güce ihtiyaç vardır. Ne kadar sıklıkla 400 kiloluk bir cisim taşınmaktadırlar? Çok çok nadirdir. Günlük hayatımızda kullandığımız spor yürümektir. Peki fiziksel olarak faydalanamayacakları bir faaliyetle neden uğraşırlar? Motivasyonları nedir? Tamamen duygusal ve sosyal deneyim içindir. Güzel görünmek, vücut için övgü almak ve kendinden emin hissetmek bazı nedenlerdir.

Deney, Yineleme ve Hata: Tasarım düşüncesi deneme-yanılma ve eylem odaklı olup, başarısılıkların öğrenimin bir parçası olarak test edilmesi ve kabul edilmesi sürecini içermektedir. İnovasyonda başarısızlık ihtimalinin azaltmanın yolu çokça hatayı kontrollü yapmaktan geçer. Takımlar başarısızlıktan sorumlu tutulmamalı, öğrenememekten sorumlu tutulmalıdır. Hipotezleri sürekli olarak test etmekte ve bulgulara göre değiştirmektedir. Minimum kaynak yatırımı ile başlamakta, zaman içinde kaynakları çoğaltmaktadır. Yeni pazar oluşturulması yüksek derecede belirsizlik ve öngörülemezlik içermektedir. Girişimcilik bir keşif sürecidir. Sorunlar nasıl keşfedilmelidir? Ne keşfedilmelidir (sorunun tanımı nedir)? Tasarım düşüncesi karmaşık sorunları tanımlamak, fırsatları keşfetmek için geliştirilmiştir. Girişimcileri keşfetme ve test etme konusunda desteklemek için birçok etnografik araç sunulmaktadır (Elliot ve Elliot, 2003: 215-220). Girişimcilerin hipotezleri sürekli olarak test edilir ve bulgulara göre değişir. Her şeyi test edilmekte ve hiçbir şey peşinen kabullenilmemektedir. Fikri test edilemeyecek bir girişim varsa, tasarım düşüncesi yatırım yapılmamasını önermektedir.

Farklı Ekip: Çapraz işlevli bir ekip, farklı uzmanlığa ve tecrübelere sahip bir gruptur. Yaratıcı çözüm farklı görüşlere sahip kişiler tarafından bir metodoloji içinde ortaya çıkmaktadır. Farklı bir ekip, tek fikirli bir yaklaşımın monotonluğunu kırar ve alternatif çözümler geliştirmektedir. Bir problem için en iyi performansı sergileyen en yetenekli takım değil, süreci takip eden en çeşitli takımdır (Standford Design School, 2009).

Farklı ve Yakınsak Düşünme: Bir ekibin ilk aşamada düşüncelerini genişletmesi, farklılaştırması, sorunlu alanları için çoklu girdilere izin vermesi gerekmektedir. Sorun bütünsel olarak anlaşılıp, alternatif çözüm önerileri üzerinde düşünülür. İnovasyon sürecinin ikinci aşaması, fikirleri eyleme geçirmeyi, daha yakınsak (daraltılarak) düşünmeyi benimsemeyi ve yenilikçi bir çözüm kullanmayı gerektirmektedir. Alternatifler değerlendirilip kaynakların kısıtlığı altında tek çözüm üzerinden prototip geliştirilip test yapılmalıdır.

Deneyimsel Ürün: Tasarım düşüncesi insanlar için olumlu deneyimler yaratmayı amaçlamaktadır. Süreç, duygusal, kültürel, bilişsel veya sosyal ihtiyaçların keşfedilmesi ve daha sonra gereksinimleri karşılamak için ürünlerin sağlanmasıyla devam etmektedir. Araştırmacı, kullanıcıyla empati kurmayı ve kullanıcının isteklerini ortaya çıkarmayı amaçlamaktadır. Ürün müşterilerin ihtiyaçlarına göre şekillenir. Ekonomide, otomobiller, uçaklar, tatiller, evler ve telefonlarda fonksiyonel ihtiyaçlar karşılamaktadır. İnsanlar bu aletleri örneğin uçağı, uçmak için kullanmazlar. Arkadaşlarıyla buluşup özel zamanları beraber geçirmek için bir turistik seyahatte bulunmak isterler (Pine ve Gilmore, 2011: 107-112). Tasarım düşüncesi uzmanları deneyimi tasarlarlar.

\section{Uygulama: Genç İşsizlik}

Bir örnek çalışmada, tasarım düşüncesinin prensipleri ve metotları 1şı̆̆ında nasıl empati yakalandiğ1 ve çözüm sistematiği oluşturduğu gösterilmektedir. 16-24 yaş arası genç işsizlik sorununa odaklanma hedeflenmiştir. Özellikle de eğitim hayatından uzakta kalmış genç işsizler ön planda tutuldu. 
Bir tasarım düşüncesi ekibinin genç işsizlik özelinde probleme nasıl yaklaştığı adım adım anlatılmaktadır.

\section{Kendi hikayeni paylaşma:}

Ekipteki üyelerin kişisel hikayeleri güçlü öngörüler sunmakta ve çok farklı perspektifleri göz önünde bulunmasını sağlamaktadır (Kelley, 2005: 125):

- İlk işinize baktığınız dönemde geçirdiğiniz süreci hatırlıyor musunuz? İş bulmayı başarmanız için hangi yetenekler, sosyal ağlar ve destekler gerekiyordu?

- Genç bir adayı işe alma veya işe girme arayışında eğitmen, aile üyesi, gönüllü veya sosyal servis uzmanı olarak çalıştınız mı? Neler hatırlıyorsunuz?

\section{Başarı Hikayeleri Belirleme:}

Tasarım düşüncesinde çok önemli bir aşama başkalarından öğrenmektir. Geçmişteki en iyi uygulamalar, başarılar ve yeni gelişen çabalar incelenir. Bu başarı hikayelerinden dersler çıkartılır ve ilham alınır (Brown, 2009: 77).

- İlham almak için model alınabilecek programlar, organizasyonlar veya yaklaşımlar var $\mathrm{m} 1 ?$

- İş hayatında, kamuda, eğitim kurumlarında, vakıflarda veya genç çalışanlar arasında kendi geliştirdikleri veya ortak çalıştıkları yeni denemelerden hangi örnekler mevcuttur?

\section{Mülakatlar Gerçekleştirme:}

Farklı insanlarla mülakatlar yaparak, farklı tecrübelerden, öngörülerden bakış açıları öğrenilmektedir. Anahtar fırsatlar yakalanır ve fikir üretme sürecine geçilmektedir (Kumar, 2012: 270).

Bu zorlu konuyla ilgili olarak paydaşlarla görüşme yapılır:

- 16-24 yaşında halihazırda çalışan, okuyan, her ikisini de yapan veya hiçbirini yapanlarla

- İş verenlerle

- İnsan kaynağıyla

- Genç insanların ebeveynleri

- Okul öğretmenleri ve üniversite öğretim üyeleri

- Ekonomist, araştırmac1, siyasetçi veya sosyal hizmetliler gibi uzmanlar

- Bu konuda bambaşka bir yaklaşımı olan herhangi biri!

\section{Başkasının adımıyla ilerleme:}

$\mathrm{Bu}$ görev iş arayan genç bir kişinin ne hissettiğini anlamak için gerçekleştirilen gerçek hayattan bir deneyim sürecidir (Young, 2015: 57-59).

- İş veren şapkasını takarak giriş seviyesindeki bir genç insanla nasıl iş görüşmeleri yapardınız? Hangi soruları sorardınız? Hangi yetenekleriyle ilgilenirdiniz? Ekipteki üyeyle veya dışarıdan kişilerle görüşme yapınız ve deneyimlerinizi yazınız.

- Sahip olduğunuz beceri, sosyal ağlar ve desteklerin sizin iş bulmanızda genç bir insan olarak ne kadar yardımcı olacağını düşününüz. Genç bir kişi gibi düşünerek CV'nizi 
oluşturup karşılaşlabilecek gorluklara göre bilgilerinizin/yeteneklerinizin/ağlarınızın/desteklerinizin size nerede ve nasıl yardımcı olacağınızı ifade ediniz.

\section{Yeni Gözlerle Bakma: Alternatif Dünyalar:}

Zor bir problem çözerken sıkışıp kalınır. Bunu aşmanın yollarından biri de görünüşte alakasız bir bağlamdan ilham aramaktır (Beckman ve Barry, 2007: 47; Akın, 2019: 17).

Başka alanlardan ve yaratıcı yaklaşımlardan metaforlardan yararlanılır. Onlar bu sorunu çözseydi soruna nasıl yaklaşırlardı diye bakılır.

\section{Şaşırtan:}

$\mathrm{Bu}$ süreçte şaşırtan bilgiler, örnekler ve hikayeler hangileri? Bu şaşırtan hikayelerden hangi inovatif çözüm üretilmektedir?

\section{Prototip:}

Prototip üretilir. Fikri kelimelerle anlatılmaz ama görselleştirilir.

\section{Geri Bildirim:}

Görsellik üzerinden paydaşlardan geri bildirim alınır.

\section{Prototip:}

Eleştirilere göre prototipi değiştirilir veya ilerletilir.

\section{Geri Bildirim: Saha Çalışması}

Saha çalışması kullanıcının gerçek bir duruma karşı olan tepkisini ölçmek üzere kurgulanmış metodolojidir. Metot belirlenen hedef kitleyi sahaya götürme, daha önce belirlenmiş faaliyetlerin içine koyma ve sonra da davranışlarını incelemeyi içermektedir. Deneyimle ilgili duygu ve düşüncelerini yakalamak için gözlem ve mülakatlar gerçekleştirilir. İfadeler ve davranışlar, tatmin olmamış kullanıcı ihtiyaçlarıyla ilgili geliştirilen hipotezleri test etmek için kullanılır. Yeni prototip üzerinden paydaşlardan tekrar geri bildirim alınır (Higgins vd., 2014: $55)$.

- Saha çalışması için konu, mekân ve faaliyeti belirlenir

- Paydaşların bu deneyimi mümkün olduğu kadar gerçekçi olarak yaşaması sağlanır.

- Saha çalışması döneminde sürekli olarak paydaşlar gözlemlenir, kameraya alınır ve notlar tutulur. 


\section{Bulgular: Ön Deneme}

Tasarım düşüncesi ekibi yukarıdaki süreç takip ederek inovatif çözüm üretmektedir (Kumar, 2012: 58). Amaç, okul dışındaki gençlere sürdürebilir ve tatminkâr bir kariyer firsatı sağlamaktır.

Tasarım düşüncesi araştırması gösteriyor ki; gençler kariyer danışmanlık organizasyonlarına karşı şüpheliler ve çok teşvik edilmedikçe katılmakta isteksizler. Elde edilen iç görülerde geniş gruplara kariyer konusunda ders vermenin çok az faydalı olduğu anlaşılır. Adımlar takip edildikten sonra test edilecek ana fikir: Nasıl giysi almadan önce deneme yapılmaktaysa, kariyer içinde deneme yapılmalıdır. Bu deneme yöntemi, kariyerle ilgili karar almayı kolaylaştırır ve özellikle de gelecek yıllardaki gereksiz ve pahalı kariyer değiştirmelerinin önünü keser.

Önerilen çözüm ise liseden terk gençleri, işletme sahiplerinin, mahalle topluluklarının ve gönüllülerin destekleriyle yeteneklerini geliştirecek yeni beceriler ve umut vadeden kariyerler bulmaktır.

\section{Saha Çalışması}

Tasarım düşüncesinin saha çalışması metodu kullanılarak, gençleri değişik işletmelere ve profesyonel iş sahalarına götürerek gençlerin kendi kendilerini keşfetmeleri, güçlü ve zayıf yönlerini anlamaları, somut ve gerçek bir iş tecrübesi kazanmaları sağlanır.

Saha çalışmasında 6 genç 4 değişik işe (reklam ajansı, gayrimenkul ofisi, profesyonel fotoğraf stüdyosuna ve tiyatroya) iki gün boyunca götürülür (Kumar, 2012: 58).

Saha çalışmasında amaç, gerçek hayatı keşfetme esnasında lise terk gençlerin ilgisini neyin çektiğini ve kendilerini değerlendirmeye başlamaları konusunda gözlemlemektir. Bu faaliyetin amacı kendilerine imkân verildiğinde lise terk gençlerin olumlu yönde tepki göstereceklerine dair beklentidir.

Liseyi tamamlamadan ayrılan 16-24 yaş arası bireyler ve işverenlerle yaptıkları mülakatlarda, gençlerin gezdirilen bu işlerde bir gelecek gördüklerini ve genel izlenimleri ise hayatla daha fazla iletişimde olma, işe adama ve çalışanlardan ilham alma yolunda gayret göstermeleridir. Gençler işletmeciler ve çalışanlarla doğal çalışma ortamlarında çeşitli kariyer seçeneklerini konuşurlar. Öğrenciler kendilerine neyin uygun neyin uygun olmadığını anlarlar ve gereken ayarlamaları yaparlar.

Somut olarak işletmeleri görmeleri, gençler açısından katıldıkları programlar sonucunda elde edecekleri sertifikaların inandırıcılığını artacağı yönündeki inancı pekiştirir.

Gençlerin profesyonel sosyal ağlarını geliştirecek faaliyetlere kanalize etmek gerekir.

\section{Sonuç}

İnovasyon süreci öğrenmeden bir kişiye inovatif olma konusunda baskılamak aslında ondan imkânsızı istemekle eş değerdir. Kişinin her şeyden önce gerekli metodolojiyi öğrenmesi gerekir. Tasarım düşüncesi yöntemiyle bir sorun özü itibariyle anlaşılır, başka kaynaklardan ilham alınarak fikirler üretilir ve test amaçla prototipler yapılır. Bu bakımdan, tasarım düşüncesi bir süreçtir ve inovasyonun yaratıcılıktan çok bir disiplin işi olduğunu savunur. Nitekim, yaratıcılığın dahi ortaya çıkışı çok çalışmak ve belli bir yöntemin izlenişine bağlı olduktan sonra, yaratıcılığın salt hayal kurma eylemiyle kendini gösteremeyeceği aşikârdır. Hayali hayata çevirmek için üzerinde oynamak, kurcalamak, test etmek gereklidir. 
Tasarım düşüncesinde inovasyonun başlangıcı sahadaki paydaşların bilgisine sahibi olmaktır. Sistemin temelindeki felsefe karşı tarafın duygularını tanımaya yönelik bir empatik bilgi arayışı1ır.

Bu çalışmada ekonomik ve eğitimsel bir problem gibi görünen genç işsizliğe odaklanıldı. Bununla birlikte, belirlenen sorunun yerine hayatta karşılaşılan herhangi bir sorun da konulabilir. Aynı prensiplerle ilerlenmektedir.

Tasarım düşüncesinde şu adımlar takip edilir:

$\checkmark$ Kendi hikayenizi paylaşma

$\checkmark$ Başarı hikayelerini belirleme

$\checkmark$ Mülakatlar gerçekleştirme

$\checkmark$ Başkasının adımıyla ilerleme

$\checkmark$ Yeni gözlerle bakma: Alternatif dünyalar

$\checkmark$ Şaşırtan noktaları bulma

$\checkmark$ Prototipleme

$\checkmark$ Geri bildirim alma

$\checkmark$ Prototipleme

$\checkmark$ Geri bildirim alma: Saha çalışması

Son 4 aşamada özellikle prototiplemenin geri bildirim alınarak yenilenerek ilerlenmesi yaparak öğrenme sürecinin sonucudur. Özellikle çözüm sahadaki testlerde kullanıcıların davranışlarında teyit edilmektedir.

Bu süreci takip etmede amaç sorunu paydaşlarla empati kurarak içselleştirmektir. Paydaş haritasında mülakat yapılması için en başta belirlenenler: 16-24 yaşında hali hazırda çalışan, okuyan, her ikisini de yapan veya hiçbirini yapanlarla iş verenlerdir. Prototip ve geri bildirim etaplarının tekrar edilmesinin sebebi deneme-yanılma süreciyle öğrenilmektedir. Her prototipte edinilen deneyime göre kâğıt üzerinden çalışmaktan sahada küçük denemeye geçiş sağlanmaktadır.

Çözüm odağında da bu iki tarafı karşılıklı getirerek gençlerin ve iş verenlerin beklentileri ortaya konulmaktadır. Gençlerin kendilerini hangi iş koluna sıcak hissettiklerini ve nerede hayal ettiklerini pratikte öğrenmeleri gerçekleştirilmektedir.

$\mathrm{Bu}$ çalışmanın esas gayesi kamu ve özel sektöre ait bir sorunu nasıl çözüme kavuşturulacağı konusunda IDEO tarafından gerçekleştirilen bir sistem etrafında aydınlatmaktır. Sorunda kişinin kendi bilgisine dayanarak tek başına çözüm üretilerek ilerlenemez. Ekip halinde, paydaşlarla görüşülerek, farklı bakış açılarından faydalanılarak, prototipleri test ederek ilerlenir.

\section{Kaynaklar}

Akın, M.Ş. (2019). Farklı bakış açısı kazanmak için beyin firtınası modelleri. Süleyman Demirel Üniversitesi Vizyoner Dergisi, 10(23),15-24.

Akın, M. S. (2020). Advanced design thinking model for innovation and entrepreneurship: ethnographic, brainstorming, prototyping (EBP Canvas Method). Berlin: Lambert Publishing.

Bahçeşehir Üniversitesi Ekonomik ve Toplumsal Araştırmalar Merkezi (BETAM) (2019). Ne eğitimde ne istihdamda (NENI). https://betam.bahcesehir.edu.tr/kategori/ekonomikarastirmalar/ 
Beckman, S. L. \& Barry, M. (2007). Innovation as a Learning Process: Embedding Design Thinking, California Management Review, 50(1), 25-49.

Beverly R I. (2013). Design Thinking for Entrepreneurs and Small Businesses: Putting the Power of Design to Work. New York: A press.

Brown, T. (2008). Design thinking. Harvard Business Review, 5(3), 56-65

Brown T. (2009). Change by design: how design thinking transforms organizations and inspires innovation. New York: Harper Business.

Caddick, R. \& Cable, S. (2011). Communicating the user experience: a practical guide for creating useful ux documentation. New York: Wiley

Dorst, K. (2011). The core of 'design thinking' and its application. Design Studies, 32(6), 521532.

Elliot, R. ve Elliot N.J., (2003). Using Ethnography in Strategic Consumer Research. Qualitative Market Research: An International Journal, 6(4), 215-223.

Bill \& Melinda Gates Foundation (2013). The silent epidemic: perspectives of high school dropouts.

Higgins, A.,Hodgson, P., Travis, D. (2014). Bright Ideas for User Experience Researchers!, London: Ebook.

Kelley, T. (2005). The ten faces of innovation. New York:Doubleday.

Klein, L. (2013). UX for lean startups: faster, smarter user experience research and design. New York: O’Reilly Media.

Kumar, V. (2012). 101 design methods: a structured approach for driving innovation in your organization. Chicago: Wiley,

Lee, V. E. ve Burkam, D. (2003) Dropping out of high school: the role of school organization and structure. American Educational Research Journal, 40(2):353-393 ·

Liedtka J. \& Ogilvie, T. (2011). Designing for Growth. New York: Columbia Business School.

Liedtka, J., King, A. \& Bennett, K. (2014). Solving Problems with Design Thinking, New York: Columbia Business School.

Luma Institute. (2014), Innovation taxanomy. Harvard Business Review, January/February, 5556

Moisander, J. \& Voltanen, A (2011), Interpretive Marketing Research: Using Ethnography in Strategic Market Development. in Lisa Penaloza; Nil Toulouse and Luca M. Viscont1 (Eds.), Marketing Management: A Cultural Perspective, First Edition, London: Routledge.

OECD (2020). Social Indicator. www.oecd.org

Pine, J., Gilmore, J. (2011), The Experience Economy. Cambridge: Harvard Business Review Press.

Standford Design School (2009), d.school bootcamp bootleg. www.dschool.standford.edu http://www.youtube.com/watch?v=-FzFk3E5nxM (20.03.2019)

Young, I. (2015). Practical Empathy: For Collaboration and Ceativity in Your Work. Rosenfeld Media.

Zaltman, G. (2003). How customers think: essential insights into the mind of the markets. Boston: Harvard Business School Press 